\title{
ADIÇÃO DO PLASMA SEMINAL AO SÊMEN OVINO DESCONGELADO
}

\author{
Liana Vieira Rocha ${ }^{1}$, Claudio Andres Reatamal ${ }^{2}$ Célia Raquel Quirino ${ }^{3}$, Angelo Burla Dias ${ }^{4}$
}

1 - Médica veterinária autônoma, MSc

2 - Professor, DS, Laboratório de Biologia Celular e Tecidual-UENF

3 - Professora, DS, Laboratório de Genética Molecular Aplicado à Produção Animal, UENF

4 - Professor, DS, Laboratório de Reprodução e Melhoramento Genético Animal-UENF - aburla@uenf.br

\section{RESUMO}

A grande variabilidade na constituição do plasma seminal pode explicar as diferenças individuais nas respostas ao congelamento e na fertilidade após a inseminação artificial em ovinos. Esse trabalho teve como objetivo avaliar o efeito da adição de um pool de plasma seminal concentrado ao sêmen ovino após descongelamento. Os ejaculados de doze carneiros da raça Santa Inês foram coletados com vagina artificial, diluídos em tris/ge$\mathrm{ma} /$ glicerol e congelados em um congelador de sêmen e embriões. Após o descongelamento foi realizada a incubação dos espermatozóides com o plasma seminal concentrado (10x), durante 15 minutos. O sêmen foi submetido à análise bioquímica, avaliação computadorizada de suas características físicas, teste hiposmótico e teste de termo-resistência. A análise eletroforética do plasma seminal apontou diferenças individuais na constituição protéica das amostras, as quais foram amenizadas com o pool de plasma seminal. Amostras tratadas com o plasma seminal apresentaram redução da motilidade progressiva. Nas demais características seminais analisadas não houve diferença $(\mathrm{p}<0,05)$ entre as amostras tratadas com o plasma seminal e as amostras controle. O pool de plasma seminal concentrado não melhorou as características seminais analisadas.

PALAVRAS-CHAVE: carneiros, congelamento, sêmen, eletroforese

\section{ABSTRACT}

\section{ADDITION OF SEMINAL PLASMA TO FROZEN-THAWED RAM SEMEN}

The considerable variability in constituents of seminal plasma could explain the particular differences in responses to freezing and in fertility rates after artificial insemination in ovines. This study assessed the effect of a pool of concentrated seminal plasma on ovine semen after thawing. Ejaculates of 12 Santa Inês rams were collected using an artificial vagina, diluted in Tris/egg yolk/glycerol and frozen in a semen and 
embryo freezer. After thawing, sperms were incubated using concentrated seminal plasma (10X) for $15 \mathrm{~min}$. Semen was submitted to biochemical analysis, followed by a computerized assessment of its physical characteristics, hypoosmotic test and heat resistance evaluation. The electrophoretic analysis of seminal plasma indicated particular differences in the samples protein composition,

KEYWORDS: Rams; Freezing; Semen; Electrophoresis

\section{INTRODUÇÃO}

A inseminação artificial com sêmen congelado ainda é pouco utilizada na ovinocultura, em decorrência da baixa tolerância do sêmen ovino à criopreservação, com consequente diminuição de sua viabilidade e capacidade fertilizante (EVANS \& MAXWELL, 1990; WATSON, 2000; KERSHAW et al., 2005). Os danos básicos provocados nos espermatozóides pela criopreservação podem ser estruturais, bioquímicos ou funcionais, sendo os estruturais geralmente mais severos para o sêmen ovino (SALAMON \& MAXWELL, 2000). Esses danos ocorrem principalmente sobre a membrana plasmática e acrossomal (PARKS \& GRAHAM, 1992; WATSON, 1995).

Há evidências consideráveis da influência do plasma seminal sobre a resistência de espermatozóides ao choque térmico e sua capacidade de sobreviver após o descongelamento (PURSEL \& JONHSON, 1975). Efeitos benéficos da utilização do plasma seminal na criopreservação de espermatozóides de equinos (AURICH et al., 1996; KATILA et al., 2002; BARRETO et al., 2008), bovinos (RONCOLETTA et al., 2002), humanos (BEN et al., 1997), suínos (METZ et al., 1990) e ovinos (GHAOUI et al., 2007) têm sido descritos. Esses efeitos são devidos, possivelmente, à interação de proteínas do plasma seminal com os espermatozóides, o que pode influenciar sua capacidade fertilizante e a proteção da membrana espermática ao choque térmico (BARRIOS et al., 2000).

O plasma seminal é constituído por secreções testiculares, epididimárias e das glândulas sexuais acessórias do macho (HENALUT et al., 1995). As contribuições químicas desses locais para o plasma seminal variam e a natureza de todos os componentes individuais não é conhecida. Uma variação na presença, ausência ou concentração desses componentes, principalmente proteínas, pode ser responsável pela variabilidade dos efeitos prejudiciais ou which were attenuated by the seminal plasma pool. The samples treated with seminal plasma showed progressive reduced motility. No statistically significant difference was observed in the other semen characteristics $(p<0.05)$, between samples treated with seminal plasma and control samples. The concentrated seminal plasma pool did not improve the assessed semen characteristics.

benéficos na funcionalidade dos espermatozóides (MAXWELL \& JOHNSON, 1999; ZHU et al., 2000), sendo a estação do ano um importante fator responsável por essa variação (CARDOZO et al., 2006).

O presente trabalho foi desenvolvido com o objetivo de avaliar o efeito da adição de um pool de plasma seminal ao sêmen descongelado de ovinos da raça Santa Inês.

\section{MATERIAL E MÉTODOS}

Foram utilizados doze ovinos da raça Santa Inês, com idade superior a um ano, em bom estado sanitário e nutricional. Os ovinos foram provenientes de propriedades privadas, localizadas no município de Campos dos Goytacazes - RJ.

As coletas das amostras ocorreram sempre após três dias de uma coleta prévia, para padronizar os ejaculados quanto ao tempo de abstinência sexual. As coletas dos ejaculados foram realizadas pelo método da vagina artificial que teve a temperatura interna ajustada para 41 a $44^{\circ} \mathrm{C}$.

Após a coleta, o sêmen foi mantido a $37^{\circ} \mathrm{C}$ para avaliação das características físicas (motilidade e vigor). Aqueles ejaculados com mais de $70 \%$ de motilidade e vigor maior que 3,0 foram utilizados para congelamento ou para obtenção do plasma seminal. Neste último caso, os ejaculados foram identificados, mantidos em gelo e centrifugados a $1100 \mathrm{x}$ g por 30 minutos, para separação do sobrenadante (plasma seminal). A esse sobrenadante foi adicionado $0,1 \mathrm{mM}$ de PMSF (Sigma ${ }^{\circledR}$, Saint Louis, USA), $1 \mathrm{mM}$ de benzamidina (Sigma ${ }^{\circledR}$ ) e $0,001861 \mathrm{~g}$ de ED$\mathrm{TA} / \mathrm{mL}$ (BioRad ${ }^{\circledR}$, Richmond, USA), para inibição da ação de proteases. Em seguida, as amostras (12) foram estocadas a $-20^{\circ} \mathrm{C}$. Posteriormente, o plasma seminal de todos os carneiros foi descongelado e misturado (pool).

O pool de plasma seminal foi submetido à ultracentrifugação a $40.000 \mathrm{x}$ g, numa ultracentrífuga 
(Himac CP $75 \beta$, marca Hitachi, Japão), a $4{ }^{\circ} \mathrm{C}$ por 45 minutos. Em seguida, o pool de plasma seminal foi concentrado dez vezes, em um concentrador proteico (Amicon 10, Millipore, EUA) utilizando-se membrana filtrante (Amicom 10.000, Millipore, EUA) e pressão de 25 Psi. Essa membrana tem a capacidade de reter proteínas com massa molecular superior a $10 \mathrm{kDa}$. Durante todo o processamento, as amostras foram mantidas em gelo. Posteriormente, as amostras foram distribuídas em alíquotas e armazenadas a $-70^{\circ} \mathrm{C}$.

Três alíquotas foram descongeladas para a determinação da concentração de proteínas totais, realizada pelo método de BRADFORD (1976), utilizando-se albumina sérica bovina (BSA) como padrão. As amostras foram ensaiadas em duplicata, com as concentrações de BSA variando de 0 a 20 $\mu \mathrm{g}$, com intervalos de $2 \mu \mathrm{g}$. As leituras foram realizadas em espectrofotômetro (Spekol UV VIS 3.01), a $595 \mathrm{~nm}$ de comprimento de onda.

As eletroforeses $(n=3)$ unidimensionais em géis de poliacrilamida $12 \%$ de amostras do plasma seminal foram realizadas em condições desnaturantes (LAEMMLI, 1970). Após a migração eletroforética, os géis foram corados com azul de Coomassie R 250 (0,1\%), em metanol (40\%) e ácido acético (10\%). A coloração foi realizada em recipiente tampado, com o gel imerso no corante, sendo submetido ao aquecimento em duas etapas, utilizando-se um forno de micro-ondas na potência máxima, até atingir a temperatura de ebulição.

As massas moleculares aparentes das proteínas do plasma seminal foram calculadas por comparação da sua mobilidade eletroforética com proteínas de massa molecular conhecida, que migraram no mesmo gel. A quantidade relativa das diversas proteínas foi determinada por densitometria, utilizandose o programa computacional Gel Perfect (BOZZO \& RETAMAL, 1991).

Após o cálculo da concentração espermática, os ejaculados $(\mathrm{n}=12)$ foram diluídos para atingir uma concentração final de $100 \times 10^{6}$ espermatozóides/mL. Ao sêmen foi adicionada a fração $\mathrm{A}(\mathrm{Fa})$ do diluidor à base de tampão TRIS, a $37^{\circ} \mathrm{C}$. Em seguida, o sêmen foi colocado num congelador de sêmen e embriões (modelo K-75, Haake, Alemanha) para iniciar o processo de resfriamento, numa velocidade de $-0,5^{\circ} \mathrm{C} / \mathrm{min}$ até atingir $5^{\circ} \mathrm{C}$. Após duas horas, a fração contendo glicerol $(\mathrm{Fb})$ foi adicionada em três etapas $(40 \%, 30 \%$ e $30 \%)$, com intervalo de $10 \mathrm{mi}-$ nutos entre elas, obtendo-se ao final da diluição uma concentração de $7 \%$ de glicerol. O sêmen foi envasado em palhetas plásticas de $0,25 \mathrm{~mL}$, que foram colocadas a uma distância de $6,0 \mathrm{~cm}$ da superfície do nitrogênio líquido, por um período de 15 minutos. Em seguida, as palhetas foram imersas no nitrogênio líquido e armazenadas em botijão criogênico. $\mathrm{O}$ descongelamento das palhetas foi realizado em banho-maria a $37^{\circ} \mathrm{C}$, por 30 segundos.

Após o descongelamento o sêmen foi incubado por 15 minutos na ausência (T0) ou na presença do plasma seminal concentrado 10x (9:1 vv) (T10), em banho-maria a $37^{\circ} \mathrm{C}$. Após a incubação o sêmen foi analisado quanto à motilidade, vigor, teste hiposmótico e de termo-resistência. A avaliação computadorizada das características físicas do sêmen (motilidade total, motilidade progressiva e vigor) foi realizada utilizando-se um programa computacional (Ceros, versão 10.2, da Hamilton Torn Research - HTR, Beverly, USA).

Para realização do teste hiposmótico as amostras de sêmen $(\mathrm{n}=12)$ foram centrifugadas por 10 minutos a $600 \mathrm{x}$ g e o pellet resultante foi ressuspendido em $1 \mathrm{~mL}$ de meio TALP e mantido por 20 min, a $37^{\circ} \mathrm{C}$. Em seguida, uma alíquota de $10 \mu \mathrm{L}$ foi adicionada a $300 \mu \mathrm{L}$ de uma solução de $100 \mathrm{mOsm}$ ( $9 \mathrm{~g}$ de frutose e $4,9 \mathrm{~g}$ de citrato de sódio/litro) e mantida por 30 minutos, a $37^{\circ} \mathrm{C}$. Para cada amostra foram contadas 200 células, sendo consideradas normais, ou seja, com membrana plasmática funcional (reação positiva) as células com cauda enrolada; e alteradas (reação negativa) aquelas com cauda esticada. A avaliação foi feita com auxílio de um microscópio de contraste de fase e os resultados expressos em porcentagem de células com membrana plasmática funcional.

$\mathrm{O}$ teste de termo-resistência foi realizado incubando-se as amostras de sêmen a $38^{\circ} \mathrm{C}$, por três horas (CBRA, 1997). A avaliação computadorizada de motilidade total e progressiva foi realizada em intervalos de uma hora, com auxílio do programa computacional Ceros 10.2 (HTR).

A análise estatística dos dados foi realizada utilizando-se o SAS (STATISTICAL ANALYSIS SYSTEM, 1996), procedendo-se a análise de consistência dos dados e as características descritivas das características estudadas (médias, desvios-padrões, valores máximos e mínimos, coeficiente de variações e teste de normalidade). Em seguida, para todas as características estudadas, foi realizada a 
análise de variância para verificar o efeito do tratamento (PROC GLM, SAS) e o teste de médias (teste "t" ao nível de $5 \%$ de probabilidade).

\section{RESULTADOS}

A concentração de proteínas totais do pool de plasma seminal, determinada pelo método de Bradford, foi de $222,5 \mathrm{mg} / \mathrm{mL}$.

A análise dos géis em SDS-PAGE de proteínas do plasma seminal de carneiros permitiu identificar um máximo de 25 bandas protéicas. As bandas majoritárias foram as de massa molecular de aproximadamente 107, 88, 64, 58, 54, 47, 28, 26, 25, 23 e $22 \mathrm{kDa}$ (Figura 1). Pôde-se notar que existem diferenças individuais marcantes entre os perfis de cada animal, de maneira quantitativa e qualitativa (presença ou ausência de bandas). As quantitativas foram encontradas principalmente na faixa entre $188 \mathrm{e}$ $68 \mathrm{kDa}$.

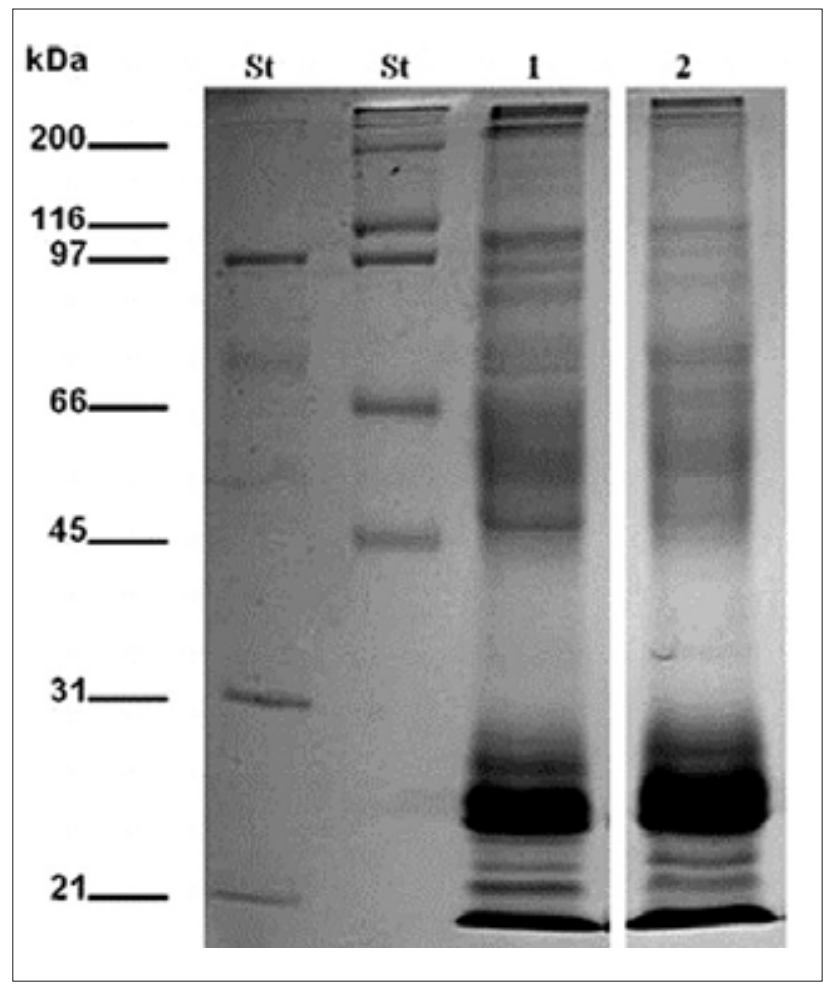

Figura 1: Gel de poliacrilamida de proteínas de plasma seminal ovino. SDS-PAGE $12 \%$ corado com azul de Coomassie. Marcadores de peso molecular (St) e seus pesos correspondentes estão dispostos à esquerda. $O$ canal 1 contém proteínas do plasma seminal in natura de um carneiro. No canal 2 estão as proteínas do pool de plasma seminal, filtrado com membrana de $10 \mathrm{kDa}$ e congelado.
A comparação das análises densitométricas entre as amostras de plasma seminal in natura e o pool filtrado em membrana de $10 \mathrm{kDa}$ e armazenado a $-70^{\circ} \mathrm{C}$ mostrou um perfil proteico muito similar entre essas amostras.

O sêmen avaliado logo após a coleta apresentou valores médios de 95,29 $\pm 3,81 \%$ para motilidade total, $83,64 \pm 3,75 \%$ para motilidade progressiva e $3,93 \pm 0,59 \%$ para vigor.

Dados referentes à motilidade total, motilidade progressiva e vigor das amostras seminais incubadas durante 15 minutos, na presença (T10) ou ausência (T0) do plasma seminal concentrado estão apresentados na Tabela 1. Não foi observada diferença $(\mathrm{p}<0,05)$ na motilidade total e no vigor espermático de amostras dos tratamentos T0 (controle) e T10 $(52,57 \pm 22,08 \%$ x $45,65 \pm 21,07 \%$ e $2,35 \pm 0,66 \times 2,07 \pm 0,72 \%$, respectivamente). Entretanto, as amostras tratadas com o plasma seminal concentrado apresentaram redução $(\mathrm{p}<0,05)$ nos valores médios da motilidade progressiva $(10,30 \pm 6,99 \% \times 4,35 \pm 3,67 \%)$.

Tabela 1: Influência do plasma seminal sobre parâmetros físicos do sêmen ovino descongelado

\begin{tabular}{ccccc}
\hline \multirow{2}{*}{ Tratamento } & $N$ & MT (\%) & MP (\%) & Vigor (\%) \\
\cline { 3 - 5 } & & (Média \pm DP) & (Média \pm DP) & (Média \pm DP) \\
\hline T0 & 40 & $52,57 \pm 22,08^{*}$ & $10,30 \pm 6,99^{*}$ & $2,35 \pm 0,66^{\star}$ \\
T10 & 40 & $45,65 \pm 21,07^{*}$ & $4,35 \pm 3,67^{\circ}$ & $2,07 \pm 0,72^{\star}$ \\
\hline
\end{tabular}

Letras distintas nas colunas indicam valores diferentes $(\mathrm{p}<0,05)$ $\mathrm{MT}=$ motilidade total; $\mathrm{MP}=$ motilidade progressiva; $\mathrm{DP}=$ desvio padrão. $\mathrm{T} 0=$ controle; $\mathrm{T} 10=$ adição de plasma seminal $10 \mathrm{x}$ concentrado.

A avaliação da funcionalidade da membrana plasmática dos espermatozóides realizada pelo teste hiposmótico não mostrou diferença estatística $(\mathrm{p}<0,05)$ entre amostras controle $(\mathrm{T} 0-41,35 \pm$ $11,32 \%)$ e amostras tratadas com o plasma seminal concentrado ( $\mathrm{T} 10-39,50 \pm 11,01 \%)$.

Após as três horas do teste de termo-resistência observou-se que as amostras tratadas com o plasma seminal concentrado apresentaram maiores percentuais de motilidade total e progressiva; contudo esses valores não foram significativamente diferentes ao nível de $\mathrm{p}>0,05$ (Tabela 2). 
Tabela 2: Valores médios obtidos durante o teste de termo-resistência (TTR) nas amostras de sêmen descongelado de ovino, segundo o tratamento, após três horas do processamento

\begin{tabular}{cccc}
\hline Tratamento & $n$ & $\begin{array}{c}\text { MT } \\
(\% \pm \text { DP })\end{array}$ & $\begin{array}{c}\text { MP } \\
(\% \pm D P)\end{array}$ \\
\hline T0 & 14 & $48,78 \pm 19,52^{a}$ & $7,28 \pm 5,13{ }^{a}$ \\
T10 & 14 & $60,48 \pm 17,14^{a}$ & $11,92 \pm 8,74^{a}$ \\
\hline
\end{tabular}

Médias seguidas de letras iguais na mesma coluna não diferem entre si $(\mathrm{p}<0,05)$

$\mathrm{MT}=$ motilidade total $\mathrm{MP}=$ motilidade progressiva $; \mathrm{DP}=$ desvio padrão. $\mathrm{T} 0=$ controle; $\mathrm{T} 10=$ adição de plasma seminal $10 \mathrm{X}$ concentrado.

\section{DISCUSSÃO}

Tem sido demonstrado que o plasma seminal atua na manutenção da motilidade e viabilidade espermática (MAXWELL et al, 1996), além de aumentar a resistência dos espermatozóides ao choque térmico (MORTIMER \& MAXWELL, 2004). Entretanto, a grande variabilidade na constituição do plasma seminal, principalmente em seu conteúdo protéico, pode explicar as diferenças individuais na funcionalidade de espermatozóides, resultando em diferentes respostas ao congelamento e fertilidade após a inseminação artificial (MAXWELL \& JOHNSON, 1999). Neste trabalho foi utilizado um pool de plasma seminal visando reduzir essa variabilidade.

A quantificação de proteínas totais do pool de plasma seminal certificou que a concentração do material filtrado e concentrado foi aproximadamente dez vezes maior $(222,5 \mathrm{mg} / \mathrm{mL})$ que a média descrita por GHAOUI et al. (2007) para o plasma seminal in natura de ovinos $(26,6 \mathrm{mg} / \mathrm{mL})$.

A análise do gel de proteínas do pool de plasma seminal demonstrou que o processamento das amostras (preparação, concentração e congelamento) não promoveu alterações no perfil eletroforético, sendo esse comparável ao perfil de amostras in natura. A análise do perfil eletroforético ainda permitiu verificar que a mistura do plasma seminal de vários animais reduziu as variações qualitativas $\mathrm{e}$ quantitativas das bandas protéicas encontradas.

Nas condições deste trabalho, as proteínas majoritárias encontradas no plasma seminal de carneiros da raça Santa Inês foram as de peso molecular em torno de 107, 88, 64, 58, 54, 47, 28, 26, 25, 23 e $22 \mathrm{kDa}$ (Figura 1), sendo as bandas de 26 e 25
$\mathrm{kDa}$ as que apresentaram maior área relativa, o que difere do perfil eletroforético do plasma seminal de carneiros da raça Guirra. MARCO-JIMÉNEZ et al. (2008) descreveram que $80 \%$ das proteínas do plasma seminal de carneiros dessa raça foram representadas por frações de proteínas de peso molecular em torno de 50, 24, 21 e $15 \mathrm{kDa}$. No entanto, JOBIM et al. (2005), utilizando-se da eletroforese bidimensional, também encontraram spots mais proeminentes abaixo de $30 \mathrm{kDa}$, ao avaliar um pool de plasma seminal de três carneiros. As bandas protéicas de 23,3 e 25,2 kDa descritas por DOMÍNGUES et al. (2008) no plasma seminal de carneiros apresentaram reação cruzada com anticorpos contra RSVP20, uma proteína de origem na vesícula seminal e responsável pela proteção dos espermatozóides contra o choque térmico. Essas bandas podem corresponder às bandas de 23 e $25 \mathrm{kDa}$ encontradas no presente trabalho.

A composição protéica do plasma seminal pode ser influenciada por vários fatores, entre eles a estação do ano, sendo descritas mudanças no conteúdo protéico e na atividade de algumas enzimas (MARTI et al., 2007). A elevação do conteúdo de proteínas totais no plasma seminal foi evidenciada durante os meses da estação reprodutiva, enquanto a maior atividade das enzimas antioxidantes ocorreu nos meses fora dessa estação (DOMÍNGUEZ et al., 2008).

Relatos conflitantes a respeito do efeito do plasma seminal sobre a motilidade espermática têm sido publicados. Espermatozóides ejaculados de ovinos, lavados e ressuspendidos em plasma seminal, ou em meio Tyrode modificado (TALP) antes da diluição no meio de criopreservação, resultaram em maiores percentagens de espermatozóides móveis que os ressuspendidos em meio Tyrode's (TALP), após resfriamento a $5^{\circ} \mathrm{C}(52 \%$ vs $35 \%)$ e após o descongelamento (14 vs 9\%), respectivamente (GRAHAM, 1994).

Ao contrário, os resultados do presente trabalho mostraram que o plasma seminal não interferiu na motilidade total $(52,6 \%$-T0 x 45,6\% - T10); porém, ele causou uma redução significativa da motilidade progressiva (de 10,3\% para 4,35\%). A redução da motilidade tem sido relacionada com a presença de fatores no plasma seminal, tais como uma fração protéica da glândula bulbo uretral, descrita em caprinos (RITAR \& SALAMON, 1982) e o fator inibidor da motilidade (SPMI) encontrado no plasma seminal 
de suínos (IWAMOTO et al., 1993).

O tempo de incubação das amostras com o plasma seminal pode ser outro fator de variação dos resultados de motilidade espermática. Essa variação pode estar relacionada ao tempo necessário para a adsorção de proteínas do plasma seminal sobre a membrana espermática. Análise por microscopia eletrônica de varredura de espermatozóides ejaculados de ovinos incubados com plasma seminal por uma hora, após exposição ao choque térmico, mostrou que os intensos danos estruturais induzidos pelo resfriamento foram revertidos após o período de incubação. Proteínas do plasma seminal que se ligaram à membrana plasmática modificaram as características funcionais de espermatozóides danificados. A avaliação da integridade de membrana com marcadores fluorescentes também indicou a restauração dos danos celulares (BARRIOS et al., 2000).

No presente trabalho foi utilizado o tempo de incubação de 15 minutos, o que pode ter sido insuficiente para a recuperação das lesões provocadas pelo resfriamento.

Recentemente, GHAOUI et al. (2007) verificaram que a ressuspensão e a incubação de espermatozóides descongelados de carneiro, por 3 e $6 \mathrm{~h}$, em plasma seminal autólogo ou sua fração sobrenadante, melhoraram as características de motilidade e a condição da membrana, reduzindo a porcentagem de espermatozóides com acrossoma reagido, possivelmente devido à ação de fatores decapacitantes presentes no plasma seminal. No entanto, esses benefícios não refletiram em melhorias na fertilidade após a inseminação cervical ou intrauterina. As taxas de gestação obtidas com a inseminação cervical e intrauterina (laparoscópica) foram de 12,7 e 45\%, respectivamente, consideradas baixas se comparadas com aquelas atingidas em programas comerciais de inseminação artificial na Austrália.

No presente trabalho, o plasma seminal não promoveu alterações relacionadas à funcionalidade da membrana plasmática, determinada pelo teste hiposmótico. A integridade e a funcionalidade da membrana espermática externa são essenciais para o metabolismo, capacitação, ligação ao ovócito e reação acrossômica. Assim, a avaliação das características da membrana pode ser adequada para predição da capacidade de fertilização dos espermatozóides (BRITO et al., 2003).
Vários procedimentos têm sido propostos para acessar características estruturais e funcionais de sêmen criopreservado de carneiros, mas nenhum deles tem mostrado uma relação consistente com a fertilidade in vivo. Nenhuma associação foi encontrada entre motilidade, viabilidade ( $\%$ de vivos) ou condição acrossomal (\% danificados, $\%$ intactos e \% reagidos) e fertilidade in vivo. Também nenhuma correlação foi encontrada entre motilidade (CASA), viabilidade, estado da capacitação, teste hiposmótico e a fertilidade in vivo de carneiros (O'MEARA et al., 2008).

Buscando correlacionar a fertilidade do sêmen bovino com testes de avaliação espermática in vitro, SIQUEIRA (2004) verificou uma correlação positiva e de média intensidade para motilidade espermática progressiva retilínea pós-descongelamento, avaliada pelo TTR, e o teste hiposmótico $(0,21)$. Entretanto, a correlação da motilidade com o teste hiposmótico foi alta $(0,64)$, demonstrando que os espermatozóides que mantiveram a integridade de sua membrana plasmática após a criopreservação permaneceram viáveis por mais tempo. Correlações negativas de média e alta intensidade $(-0,25$ e $-0,46$, respectivamente) foram encontradas para o teste de reação acrossômica com a motilidade espermática progressiva retilínea pós-descongelamento e após 3 h de incubação. No entanto, não houve correlação do TTR, teste hiposmótico, teste de reação acrossômica e motilidade pós-descongelamento com a taxa de gestação. Entretanto, BRITO et al. (2003) encontraram uma correlação positiva entre o teste hiposmótico e a taxa de fertilização in vitro de ovócitos bovinos.

Nas condições deste trabalho, o plasma seminal não mostrou efeitos positivos sobre a motilidade espermática, integridade e funcionalidade da membrana, porém é necessário investigar outras variáveis, como diferentes concentrações e tempos de incubação, visando reduzir os efeitos danosos do congelamento sobre o espermatozóide ovino.

\section{AGRADECIMENTOS}

Os autores agradecem à Fundação Carlos Chagas Filho de Amparo à Pesquisa do Estado do Rio de Janeiro (FAPERJ) pelo apoio financeiro na execução deste trabalho. 


\section{REFERENNCIAS}

AURICH, J.E., KÜHNE, A., HOPPE, H., AURICH, C. Seminal plasma affects membrane integrity and motility of equine spermatozoa after cryopreservation. Theriogenology, v. 46, p. 791-797, 1996.

BARRETO, M.A.P.; SILVA, J.F.S.; FAGUNDES, B.; CAIADO, J.R.C.; SOUZA, G. V.; SHIMOYA, A. Efeito de proteínas do plasma seminal eqüino com massa superior a $10 \mathrm{kDa}$ concentradas 10 vezes sobre a congelabilidade do sêmen. Revista Brasileira de Zootecnia, v. 37, p. 2115-2119, 2008.

BARRIOS, B., PÉREZ-PÉ, R., GALLEGO, M., TATO, A., OSADA, J., MUIÑO-BLANCO, T., CEBRIÁNPÉREZ, J.A. Seminal plasma proteins revert the coldshock damage on ram sperm membrane. Biology of Reproduction, v.63, p. 1531-1537, 2000.

BEN, W.X., FU, M.T., MAO, L.K., MING, Z.W., XIONG, W.W. effect of various concentrations of native seminal plasma in cryoprotectant on viability of human sperm. Archives of Andrology, v.39, p.211-216, 1997.

BOZZO, S., RETAMAL, C. Geles unidimensionales. Un nuevo método densitometrico para computadores personales. Archivos de Biologia Y Medicina Experimentales, v.24, p.181, 1991.

BRADFORD, M.M. A rapid sensitive method for the quantification of microgram quantities of protein utilizing the principle of protein dye binding. Analitical Biochemistry, v. 72, p.248-254, 1976.

BRITO, L.F.C.; BARTH, A. D.; BILODEAUGOESEELS, S.; PANICH, P.L.; KASTELIC, J.P. Comparison of methods to evaluate the plasmalemma of bovine sperm and their relationship with in vitro fertilization rate. Theriogenology, v.60, p.1539-1551, 2003

CARDOZO, J.A., FERNÁNDEZ-JUAN, M., FORCAD, F., ABECIA, A., MUIÑO-BLANCO, T., CEBRIÁNPÉREZ, J.A. Monthly variations in ovine seminal plasma proteins analyzed by two-dimensional polyacrylamide gel electrophoresis. Theriogenology, v.66, n.4, p. 841-850, 2006.

COLÉGIO BRASILEIRO DE REPRODUÇÃO ANIMAL Manual para exame andrológico e avaliação de sêmen animal. $2^{\mathrm{a}}$ ed. Belo horizonte, MG, 1997. http://www.cbra.org.br/portal/index.htm.

DOMÍNGUEZ, M.P., FALCINELLI, A., HOZBOR, F., SÁNCHEZ, E., CESARI, A., ALBERIO, R.H. Seasonal variations in the composition of ram seminal plasma and its effect on frozen-thawed ram sperm. Theriogenology, v.69, p.564-573, 2008.

EVANS, G.; MAXWELL, W. M. C. Inseminación artificial de ovejas y cabras. Espanha: Zaragoza, 1990.
$192 \mathrm{p}$.

GHAOUI, R. E., THOMSON, P.C., LEAHY, T., SALAMON, G., MAXWELL, W.M.C. Autologous whole ram seminal plasma and its vesicle-free fraction improve motility characteristics and membrane status but not in vivo fertility of frozen-thawed ram spermatozoa. Reproduction in Domestic Animals, v.42, p.541-549, 2007.

GRAHAM, J.K. Effect of seminal plasma on the motility of epididymal and ejaculated spermatozoa of the ram and bull during the cryopreservation process. Theriogenology, v. 41, p. 1151-1162, 1994.

HENALUT, M.A.; KILLIAN, G.J.; J.F. KAVANAAUGH, J.F.; GRIL, L.C. Effect of accessory sex gland fluid from bulls of different fertilities on the ability of cauda epididymal sperm to penetrate zona-free ovine oocytes. Biology of Reproduction, v.52, p. 390-397, 1995.

IWAMOTO T, TANAKA H, OSADA 1, SHINAGAWA T, OSAMURA Y, GAGNON C. Origin of a sperm motility inhibitor from boar seminal plasma. Molecular Reproduction and Development; v.36, p.475-481, 1993.

JOBIM, M.I.M., OBERST, E.R., SALBEGO, C.G., WALD, V.B. A.P. HORN, E.R.; MATTOS, R.C. BSP A1/A2-like proteins in ram seminal plasma. Theriogenology v.63, p.2053-2062, 2005. .

KATILA, T., ANDERSON, M., REILAS, T., KOSKINEN, E. Post-thaw motility and viability of fractionated and frozen stallion ejaculates. Theriogenology, v.58, p.241-244, 2002.

KERSHAW, C. M.; KHALID, M.; MCGOWAN, M. R.; INGRAM, K.; LEETHONGDEE, S.; WAX, G.; SCARAMUZZI, R.J. The anatomy of the sheep cervix and its influence on the transcervical passage of an inseminating pipette into the uterine lumen. Theriogenology, v. 64, p. 1225-1235, 2005.

LAEMMLI, U.K. Cleavage of structural proteins during assembly of head of bacteriophage-t4. Nature; v.227, p.680-685, 1970.

MARCO-JIMÉNEZ, F., VICENTE, J.S., VIUDES-DECASTRO, M.P. Seminal plasma composition from ejaculates collected by artificial vagina and electroejaculation in Guirra ram. Reproduction in Domestic Animals, v. 43, p. 403-408, 2008.

MARTI, E., MARA, L., MARTI, J.I., MUINÕBLANCO, T., CEBRIÁN-PÉREZ, J.A. Seasonal variations in antioxidant enzyme activity in ram seminal plasma. Theriogenology, v.67, p.1446-1454, 2007.

MAXWELL, W.M.,WELCH, G.R., JOHNSON, L.A. Viability and membrane integrity of spermatozoa after dilution and flow cytometric sorting in the presence or absence of seminal plasma. Reproduction, Fertility and Development, v.8, p.1165-1178, 1996. 
MAXWELL, W.M.C., JOHNSON, L.A. Physiology of spermatozoa at high dilution rates: the influence of seminal plasma. Theriogenology, v.52, p.1353-1362, 1999.

METZ, K.W., BERGER, T., CLEGG, E.D. Adsorption of seminal plasma proteins by boar spermatozoa. Theriogenology, v.34, p.691-700, 1990.

MORTIMER, S.T., MAXWELL, W.M.C. Effect of medium on the kinematics of frozen-thawed ram spermatozoa. Reproduction, v.127, p.285-291, 2004.

O'MEARA, C.M., HANRAHAN, J.P., PRATHALINGAM, N.S., OWEN, J.S., DONOVAN, A., FAIR, S., WARD, F., WADE, M., EVANS, A.C.O., LONERGAN, P. Relationship between in vitro sperm functional tests and in vivo fertility of rams following cervical artificial insemination of ewes with frozenthawed semen. Theriogenology, v.69, n.4, p.513-522, 2008.

PARKS, J.E., GRAHAM, J.K. Effects of cryopreservation procedures on sperm membranes. Theriogenology, v.38: p.209-222, 1922.

PURSEL, V.G., JONHSON, L.A. Freezing of boar spermatozoa: fertilizing capacity with concentrated semen and a new thawing procedure. Journal of Animal Science, v.40: p.99-102, 1975.

RITAR, A.J.; SALAMON, S. Effects of seminal plasma and of its removal and of egg yolk in the diluent on the survival of fresh and frozen-thawed spermatozoa of the Angora goat. Australian Journal of Biological Science, v.35, p. 305-312, 1982.

RONCOLETTA, M.; MORANI. E.S.C.; FRANCESCHINI, P.H. $14 \mathrm{kDa}$ seminal plasma protein identification and its relation with bull semen freezability. Theriogenology, v.57, p.479, 2002.

SALAMON, S., MAXWELL, W.M.C. Storage of ram semen. Animal Reproduction Science, v.62, p.77-111, 2000 .

SIQUEIRA, J.B. Relação da fertilidade de sêmen bovino congelado com testes de avaliação espermática "in vitro". Dissertação (Mestrado) - Viçosa MG, Universidade Federal de Viçosa - UFV, 77p., 2004. Acessível em http://www.tede.ufv.br/tedesimplificado/tde_busca/arqui vo.php? codArquivo $=301$

STATISTICAL ANALYSES SYSTEM - S. User's guide. Cary: SAS Institute., 1996.

WATSON, P.F. Recent developments and concepts in the cryopreservation of spermatozoa and assessment of their post-thaw function. Reproduction, Fertility and Development, v.7, p. 871-891, 1995.

WATSON, P.F. The causes of reduced fertility with cryopreserved semen. Animal Reproduction Science, v. 60, p. 481-492, 2000.

ZHU, J., XU, X., COSGROVE, J.R., FOXCROFT, G.R. Effect of semen plasma from different fractions of individual ejaculates on IVF in pigs. Theriogenology v.54, p. 1443-1452, 2000. 